\title{
Sobre o estatuto da sátira na obra de Jorge de Sena*
}

Marcus Vinicius de Freitas

Universidade Federal de Minas Gerais/CNPq

Poesia, te escrevia

flor! conhecendo

que és fezes.

João Cabral de Melo Neto

\section{A sátira como elo entre criação e crítica}

orge deSena é um moralista. Não dos que aviam receitas
morais, dos que prescrevem códigos de conduta, dos
que controlam o desejo do próximo. Mas sim um
reformador, um moralista que aponta os desvios para
que, pelo exemplo, o mundo se converta em um lugar melhor
para se viver. Uma profunda relação entre criação e crítica,
relação essa que tem na sátira o seu instrumento privilegiado,
é o que constitui o lugar primordial daquele exercício moral. O
exemplo que Sena quer passar não vem de proselitismos
políticos, religiosos ou filosóficos, mas deriva da criação
consciente e da expansão dessa consciência pela atitude crítica.
Na vasta obra do autor, inúmeras são as vezes em que ele
explicita a relação entre o fazer crítico e o exercício poético.

* Este trabalho integra o projeto de pesquisa "O escritor e seu ofício", financiado pela Bolsa de Produtividade em Pesquisa do CNPq. 
Todo poeta, se ele o é na extensão em que Sena compreende o termo, faz sempre crítica, ainda que não dentro desse gênero estritamente considerado. Ou seja, todo ato criador constitui, para Jorge de Sena, um ato crítico, seja sobre o mundo, sobre a linguagem ou sobre os que precederam o poeta, porque criar é tomar consciência de si no mundo, e essa busca da consciência define a condição crítica. Reciprocamente, todo ato crítico é um ato de criação, pois a tomada de consciência sobre o estar no mundo transforma esse mesmo mundo.

A indissociabilidade entre composição e crítica na obra de Jorge deSena foi muitas vezes vista apenas enquanto ecletismo, como podemos ver nesta afirmação de João Gaspar Simões:

De tudo foi um pouco, nas letras, Jorge de Sena. E depois de ter sido poeta, crítico, historiador da literatura, ensaísta, novelista, dramaturgo, morre deixando-nos uma peçamestra da arte do romance, no contexto de um gênero onde são raras, raríssimas, as peças-mestras. ${ }^{1}$

Jorge de Sena respondia com precisão a essas insinuações. Para o autor, o ecletismo era a expressão acabada do conformismo filosófico e de um "relativismo literato e nãocientífico". ${ }^{2} \mathrm{O}$ uso de diversos métodos críticos ou a presença da crítica no ato mesmo da criação são defendidos por Sena não enquanto relativismo inconsequente, mas como reconhecimento de que a realidade é complexa e de que todas as abordagens que se revelem fecundas são por isso mesmo legítimas. Lembro aqui apenas uma passagem sobre o tema, pelo seu poder evocativo:

${ }^{1}$ SIMÕES, 1984, p. 338.

2 SENA, 1977a, p. 118. 
Quando, em 1938, me estreei em letra de forma, sucedeu que o fiz com um poema e com um ensaio sobre poesia, que ambos ficaram esquecidos no modesto jornal universitário em que apareceram. Quando, em 1942, publiquei um primeiro livro de poemas, nesse mesmo ano apareci como conferencista (um estudo sobre Rimbaud). Assim, desde o início da minha carreira de escritor, o poeta e o crítico sempre foram aparecendo paralelamente; e esse padrão manteve-se até hoje. ${ }^{3}$

Essa passagem abre um texto cujo subtítulo, "Um Depoimento Sobre Algumas Décadas de Experiência Pessoal", busca enfatizar na continuidade histórica a profunda relação entre poesia e crítica que marcam a obra do autor. Essa postura, tantas vezes reiterada por Sena, e nem sempre compreendida pelos seus críticos, visava a diferentes contextos.

O primeiro deles, como corolário dessa incompreensão, é o contexto mesmo da crítica literária e cultural em Portugal, vista pelo autor, com honrosas exceções, como mesquinha, preconceituosa e, sobretudo, tecnicamente despreparada. ${ }^{4} \mathrm{~A}$ separação entre as atividades criativa e crítica só pode interessar ao crítico cujo foco são menos os objetos estéticos em si mesmos do que tal ou qual discurso político, religioso ou moral, constituídos para além dos objetos. A arte, nesse caso, é tomada apenas como pretexto para outros propósitos. Igual interesse na separação entre arte e crítica possui o crítico impressionista, alvo predileto de Jorge de Sena, pelo desserviço que presta à cultura. Comparando os dois tipos, Sena exemplifica com António Sérgio no primeiro caso (cuja integridade moral e intelectual é por ele reiterada, ao contrário

${ }^{3}$ SENA, 1977b, p. 237

${ }^{4}$ Ver SENA, 1980. 
dos críticos de partido, contra quem sua observação se volta de maneira mais clara); no segundo caso, os exemplos são dois dos mais tradicionalmente afamados críticos portugueses:

É isto [a atitude de Sérgio] por certo preferível e mais eficaz do que um crítico usar da literatura para justificar durante décadas a própria existência, como tem sido o caso de um Hernani Cidade ou de um Gaspar Simões que continuam sobrevivos, e mesmo prestigiosos, apesar da regular acumulação de tolices que vêm servindo ao público português e à inocência bibliográfica dos estudiosos estrangeiros. ${ }^{5}$

Cidade e Simões são respectivamente editores de Camões e Pessoa, não por acaso os dois objetos críticos privilegiados da obra de Sena. A edição camoniana de Cidade, com seus comentários filológicos mais normativos do que históricolinguísticos, ou o biografismo sem relação com a análise poética, que caracteriza as apresentações pessoanas de Simões, ambos constituem as piores formas da crítica impressionista, contra a qual o autor se volta. Dessa forma, enfatizar a estreita relação entre construção e crítica constitui para Sena uma estratégia de combate àquela mesma crítica.

Um segundo âmbito em que podemos compreender a defesa seniana da relação poesia/crítica é o contexto do poeta moderno, em que a secularização da arte põe a nu a função transformadora (e portanto crítica) do ato criativo, liberto das convenções políticas, sociais ou morais que classicizavam (leiase normatizavam) a apreensão de autores como Shakespeare, Dante, ou Camões, por exemplo:

${ }^{5}$ SENA, 1980b, p. 104. 
Hoje, o modernismo, como tomada de consciência, permite lê-los [aqueles autores] qual nem eles mesmos se atreveriam, e até dizer-lhes, se ressuscitassem, que, muito provavelmente, Dante não era religioso, Camões não era patriota, Shakespeare não tinha moral, Dostoiévski acumulava esses vícios todos. A grande revolução do modernismo não foi, portanto, a de inventar livremente, a de multiplicar até ao infinito as escolas e as maneiras. Se Joyce ou se Rimbaud tivessem sido só isso, toda a gente os leria sem pânico. A grande revolução foi, pelo contrário, pôr claramente e destrutivamente a sem-razão do mundo em que vivemos, e provar, pela criação, que a realidade não é conhecida senão no próprio acto de ser transformada. ${ }^{6}$

O Modernismo é então compreendido enquanto consciência crítica, enquanto fazer poético que se sabe crítico na medida em que se reconhece transformador da realidade através do ato de criação. Mais do que isso, o desvelamento da relação entre criação e consciência crítica, produzido pela laicização da arte, é o que propriamente caracteriza o Modernismo, já que a consciência transformadora não é privilégio da nossa contemporaneidade, mas atributo de toda arte e de todo autor digno do nome, como o são Dante, Camões, Shakespeare ou Dostoiévski.

$\mathrm{O}$ terceiro contexto a que se dirige a defesa seniana da íntima relação entre criação e crítica é o de um engajamento moral da arte e da crítica. Com certeza, Sena não se liga a qualquer conceito de arte engagé, termo carregado de conotações político-partidárias que repugnavam ao autor. $\mathrm{O}$ engajamento que aí ele se propõe diria respeito tão somente à atitude crítica do artista perante o próprio trabalho de criação,

${ }^{6}$ SENA, 1977a, p. 176. 
atitude essa que se revela pelo exercício da consciência e sua expansão em direção ao leitor, ao ouvinte, ao receptor da obra de arte. Numa sociedade de massas em ascensão à cultura, diz Sena, a arte não seria mais um vil artefato de sujeição ideológica ou um ornamento de classes privilegiadas. A arte e a cultura, agora, são a "... representação concreta da humanidade no seu esforço e na sua exigência de reconhecerse como tal. São essenciais à existência humana, como expressão de uma sempre acrescentada experiência da consciência livre. ${ }^{7}$ Há aqui, senão uma ingênua crença no poder libertador da arte moderna, pelo menos uma fé futurista, uma atitude pedagógica, tão ao gosto modernista, que via a arte como a vanguarda de um mundo em positiva transformação. Nesse contexto, não somente a arte, como também o seu estudo, são necessários à realização da condição humana:

$\mathrm{Na}$ ascensão dos povos à liberdade e à felicidade, há que transmitir-lhes e que ensinar-lhes a experiência da liberdade e da felicidade, que, mesmo nas mais desesperadas e mais negras obras de arte, se contém. Só a arte contém uma experiência deste mundo, e não contém mesmo outra, ainda quando fale exclusivamente e obssessivamente de outro mundo. E sem o auxílio da experiência alheia, ninguém é capaz de conceber, e portanto de apreciar e absorver, as virtualidades que as novas experiências sociais lhe oferecem. ${ }^{8}$

O conceito seniano de crítica está, como se pode depreender da passagem, ligado a uma visão pedagógica da arte, a uma visão da literatura como missão. Para ele, é necessário não somente transmitir o anseio de liberdade e felicidade, através

7 SENA, 1977a, p. 125.

${ }^{8}$ SENA, 1977a, p. 124. 
da arte que se faz, mas igualmente ensiná-lo, através da crítica que sobre a arte se tece. Transmitir e ensinar são as duas faces, a poética e a crítica, da atitude de Sena perante a arte e o papel do artista.

Daqui se torna claro o porquê de tantos e tão detalhados prefácios e notas explicativas na obra do autor. A princípio, o intuito parece ser o de controlar o modo como o leitor receberá cada conto, cada poema, dando informações sobre o momento da composição, as motivações superficiais e profundas de cada pensamento, as referências intertextuais de cada verso. Sena diz também que necessitava de fazer a própria crítica, uma vez que não havia em Portugal críticos à altura de sua obra. Ainda que ambos os motivos sejam relevantes para o autor, o que se revela primordialmente, quando nos deparamos com afirmações como aquela acima, é a profunda motivação pedagógica de sua arte, bem como de sua crítica, e por isso elas são tão integradas. Estamos diante de um moralista, no sentido profundo do termo.

Vejamos o que Sena diz a respeito, em algumas considerações relativas aos ensaios de $O$ Reino da Estupidez-I:

Se a palavra não tivesse para mim conotações detestáveis, eu proporia que são ensaios morais. Ensaios morais? É verdade. É detestável a conotação de morais? Para mim não menos verdade. O poeta e o crítico, se coexistem numa mesma pessoa - e, de certo modo, embora em graus diversos de mútua lucidez, coexistam sempre -, não podem senão transcender a insciente vivência em que os confina uma visão lírica do mundo, para atentarem, eticamente, no que o mundo é. Acontece, porém, que os juízos éticos estão, no mundo actual, falseados, pervertidos. ${ }^{9}$

SENA, 1979, p. 11-12. 
A passagem sintetiza o que tenho mostrado até aqui. Partindo da coexistência do poeta e do crítico, Sena propõe a construção de ensaios satíricos, e portanto morais, que redescubram a verdadeira dimensão ética da poesia e da crítica, pois a mesma anda submersa na atual perversão da noção de juízo ético, ou seja, de moral. Aquela dimensão ética apenas se revelaria quando a mesma poesia e a mesma crítica se ligam, visando a uma passagem do mundo do poeta à realidade.

A paixão de Sena pelo "realismo moral" de Maquiavel se explicaria nesse contexto. Contra o lugar comum que atribui maquiavelismo ao pensador italiano, Sena atesta o caráter íntegro do autor, cujo "pecado" teria sido, na concepção de Sena, o de ter desvelado que a virtude só tem valor quando ligada à transformação do mundo:

Machiavelli é pelo contrário, um moralista, na mais alta e nobre acepção da palavra: aquele que descreve os costumes humanos, os resultados a que eles conduzem, e as causas que os condicionam, com objetividade clínica. Se daí pode ser extraído, ou não, um conjunto de normas morais que rejam o bem-viver em sociedade, eis o que excede o âmbito de seu pensamento. ${ }^{10}$

Maquiavel constituiria, assim, uma imagem especular do próprio Jorge de Sena. Haveria nobreza em sua moralidade, pois ela seria fruto não de uma prescrição, mas de uma análise sobre o mundo. Cabe observar a grande contradição entre a utopia moral de Jorge de Sena e a sua repulsa aos partidarismos de toda ordem, uma vez que a natural evolução totalitária dos projetos utópicos se fundamenta exatamente numa visão utilitária da virtude. Se a virtude só tem valor

10 SENA, 1974, p. 30. 
enquanto instrumento de transformação da realidade, os fins justificariam todos os meios. Atente-se para uma citação anterior, na qual ele afirma que "a realidade não é conhecida senão no próprio acto de ser transformada", o que constitui o próprio conceito revolucionário de "praxis". E atente-se ainda para todo o vocabulário revolucionário que permeia as citações que temos visto: "revolução", "dialética", "classes privilegiadas", "transformação", "ascenção dos povos à liberdade e à felicidade". A história do século XX mostrou sobejamente onde desaguam essas certezas revolucionárias. Sob esse ponto de vista, Sena se revela quase ingênuo, uma espécie de déspota esclarecido de gabinete, um militante puro, um revolucionário moral útil, que não atina para o fato de que a submissão da condição humana a uma ética da ação e da transformação é exatamente o que perverte a mesma vivência ética que ele se propõe a defender e ensinar. Essa atitude caracteriza-o plenamente como um artista da vanguarda do século XX, com todas as suas crenças na revolução. Ao mesmo tempo, suas referências ligam essa vanguarda ao discurso moral iluminista, com raízes em Maquiavel, mas com desdobramentos perfeitamente lusos no Matias Aires da "Reflexão sobre a vaidade dos homens", o Tomás Antônio Gonzaga das "Cartas Chilenas" e o Francisco de Melo Franco do "Reino da Estupidez".

Dessa atitude de moralista, dignificada como ética realista, deriva a importância da sátira no conjunto da obra de Sena, o que pouco tem sido apontado pela crítica, ou às vezes avaliado por um prisma redutor, como no caso dos comentários antes citados de João Gaspar Simões sobre o percurso de Sena. Para aquele crítico, a veemência dos textos de $O$ Reino da Estupidez-I são, antes de tudo, fruto de uma denegação do "estrangeirado" Sena, que, em auto-exílio, ama ainda a pátria abandonada, travestindo em ódio esse amor. A solução psicologizante de Simões banaliza a importância da sátira em Jorge de Sena, além de partir de uma 
postura quase xenófoba, por ver a atitude crítica do poeta como consequência danosa do processo de "estrangeiramento". ${ }^{11}$ Se não há como compreender esse que desafia, pela sátira, as tradições críticas de Portugal, melhor rotulá-lo como "estrangeirado".

Se, por um lado, o ensaio crítico tem raízes em Montaigne, poderíamos, por outro, ver que Sena está mais próximo de Matias Aires, de Gonzaga ou de Francisco de Melo Franco, cujo livro dá título e tom aos ensaios críticos de Sena. Se a ironia é o procedimento básico da sátira seniana, como o é em Machado de Assis - outro montaigniano com leituras de Matias Aires -, Sena entretanto se distancia do autor de Brás Cubas, por propugnar uma sátira interessada, moralista, e não comungar do propalado ceticismo machadiano (tópico que merece talvez uma revisão crítica, possivelmente reveladora da mesma matriz moralista).

Na obra de Jorge de Sena, a sátira é então um dos mecanismos pelos quais a criação se torna crítica, e a poesia sai de seu mundo lírico para medir-se com a realidade. Por isso, alguns dos mais interessantes momentos de sua obra poética e ficcional são exatamente aqueles em que a sátira revela o conteúdo crítico do poema ou da narrativa. Quero debruçar-me, a título de exemplo, sobre dois desses momentos em sua poesia.

\section{Poesia e sátira}

Em vários de seus textos e comentários, Jorge de Sena anunciou a sempre adiada publicação do conjunto de poemas intitulado Dedicácias, ${ }^{12}$ composto de sátiras ao ambiente e a

11 SIMÕES, 1984, p. 76.

12 SENA, 1999a. 
personagens das culturas portuguesa e brasileira, todos seus contemporâeos, e vários ainda vivos e muito ativos. A publicação foi sempre adiada, possivelmente pelo conteúdo às vezes muito pessoal de alguns textos, o que poderia gerar suscetibilidades. Alguns anos depois da morte de Jorge de Sena, sete desses poemas vieram a público pelas mãos de Mécia de Sena. O número 6 da Revista Hífen, de fevereiro de 1991, publicou seis poemas, e o sétimo saiu como epígrafe na edição da correspondência entre Sena e Vergílio Ferreira. Em 1999, Dona Mécia fez finalmente por publicar, pela editora Três Sinais, de Lisboa, o conjunto das Dedicácias. Vários são os poemas ali presentes que sugerem bons elementos para os fins da análise em tela. Cabe antes lembrar que, na "Nota Prévia" à edição, Mécia de Sena aponta que aquele é um livro fruto de "profundo desgosto ... ou de ressentimento, por alguma maldade ou injustiça recebidas", e completa ainda a descrição dizendo que a leitura dos poemas talvez "... fará a alegria de muita gente que não conheceu ou conheceu mal o Jorge de Sena, mas muito enfaticamente lhe declara o mau gênio e os rompantes, porque, ao que parece, tal lhes alivia as suas próprias frustrações." ${ }^{13}$ Essa inversão entre riso e mágoa, a meu ver, corrobora o estatuto moral da sátira seniana.

A antiga tradição das cantigas de escárnio e maldizer sustenta o projeto de Sena. Como no caso da estabelecida compreensão da tradição medieval, poderíamos dividir inicialmente os poemas pelo critério da nomeação ou não das personagens satirizadas. Quando da publicação avulsa de seis poemas em Hífen, e mais uma na correspondência entre Sena e Vergílio Ferreira, feitas ambas por Mécia de Sena, dois dos sete poemas nomeavam os satirizados, quais sejam "Aviso à Circulação", sobre a figura de João Gaspar Simões, e "Tem

${ }^{13}$ SENA, Mécia de, 1999, p. 10. 
uma letra tão miudinha" sobre Vergílio Ferreira; os outro cinco poemas apareciam sem designação de maldizer. Dois destes últimos, intitulados ambos "Epístola a A.S.", pareciam reportarse a uma personagem individualizada, apenas escondida sob iniciais. Se partíssemos do princípio de que as iniciais visavam tão somente a esconder o nomeado, para proteger o autor de um possível revés, deveríamos levantar hipóteses para o nome escondido. Quando da publicação do livro, em 1999, Dona Mécia renomeou o maldito em tela: tratava-se de Álvaro Salema, jornalista e crítico literário muito conhecido no meio cultural português. Resta saber se a atribuição do maldizer foi feita por Jorge de Sena (e nesse caso as iniciais seriam fruto do pudor de Mécia, quando da primeira aparição dos poemas), ou se Sena mantivera-o no anonimato, para efeitos poéticos (caso em que a revelação seria atributo da esposa e editora). Penso que a primeira hipótese é mais plausível, uma vez que, no mesmo texto introdutório antes citado, Mécia de Sena declara ter decidido "... que não desvendaria o nome das pessoas que os poemas não mencionam. Aqueles que viveram esses tempos sabem bem quem o maltratou e como e onde; os outros... que busquem nos jornais, nas revistas, nas cartas, nas publicações que organizou... está tudo lá e fácil de deduzir." ${ }^{14}$ Seja como for, a voluntária ou involuntária transformação do poema de maldizer em poema de escárnio, quando da aparição original das "Epístolas", realçou o valor poético do próprio poema, e não o seu valor contextual de crítica ao satirizado. Dizendo de outra maneira, a forma do escárnio universaliza o que seria apenas maldizer. Mesmo que, na edição final das Dedicácias, grande parte das personagens seja nomeada, o efeito satírico não perde nunca de vista a busca da universalização. Imaginar que os poemas de Dedicácias tivessem valor apenas pela

14 SENA, Mécia de, 1999, p. 10. 
maldição lançada às personagens seria o mesmo que submetêlos ao processo redutor de validação apenas como instrumentos externos à arte. Ao contrário, entendo que não são necessários nomes para que a sátira se faça, uma vez que A.S. ou Álvaro Salema são sempre espaços vicários, imagens dos desvios morais que Sena quer criticar. Dizendo de outra forma, penso que os poemas de Dedicácias são melhor lidos numa clave universalizante, e não em busca das rusgas que Sena efetivamente tinha com essa ou aquela personagem. E cabe lembrar que, dos quarenta poemas constantes da edição, apenas metade (vinte poemas) traz explícito ou criptografado o nome do satirizado. Todos os outros são generalizantes. A presença ali de tantos poemas satíricos sem nomeação de maldizer atesta a possibilidade de uma leitura universalizante do conjunto. Detenho-me em um deles:

\section{Aviso à circulação}

Se de um dos poetas dos últimos cinquenta anos o Gaspar Simões escreve um elogio, e eu estimo esse poeta, quedo logo numa aflição por ele (o poeta): que defeito haverá nessa poesia para o Simões gostar tanto assim dela?

Assim como os poetas medievais nomeavam os seus oponentes, que não necessariamente eram seus inimigos, uma vez que a convenção do gênero coloca a contenda no plano literário, também Sena nomeia Gaspar Simões e satiriza seu gosto poético. Mas o intento e o alcance do poema de Sena está muito além da simples atualização de um gênero. Ele usa dessa atualização para propor e discutir questões muito contemporâneas.

Primeiramente, devemos entender que Simões, no poema, não se reduz a um indivíduo isolado, mas constitui a imagem de um tipo de crítico visado pelo olhar de Jorge de Sena. E é 
aqui que a retomada do gênero antigo ganha seu sentido novo. O pastiche da forma tradicional não é apenas um exercício de erudição, mas uma estratégia poética e crítica. Pois, o que define a personagem Simões? Ser um crítico cujo comentário se reduz ao elogio. Elogiar ou atacar são ações que reduzem a crítica ao plano do gosto, ou seja, ao impressionismo, contra o qual Sena sempre se voltou. Como contrapartida, o eu-lírico enuncia sua posição baseando-se não em gosto, mas em técnica, já que sua dúvida é sobre a existência ou não de um defeito na obra analisada, signo este que aponta para a fatura do objeto artístico. As relações podem ser assim representadas:

$$
\begin{aligned}
& \text { Simões } \rightarrow \text { elogio } \rightarrow \text { gosto } \\
& \text { Eu-lírico } \rightarrow \text { defeito } \rightarrow \text { construção }
\end{aligned}
$$

Ao mesmo tempo, cabe lembrar que o possível autor discutido pelo poema é "um poeta dos últimos cinquenta anos". A expressão aponta exatamente para o Modernismo, como a dizer que Simões não é um crítico capaz de analisar uma obra moderna, definida por Sena como aquela em que as relações entre criação e crítica são explicitadas. Portanto, as oposições criadas entre Simões e o eu-lírico seniano, entre o elogio e o defeito, entre o gosto e a análise da construção apontam todas para a relação, defendida pelo poeta moderno, entre criação e crítica.

A função da sátira nas Dedicácias parece-me estar assim ligada a toda a discussão seniana sobre a intrínseca ligação entre poesia e crítica, e sobre o sentido pedagógico dessa crítica, muito mais do que a um simples gosto pela blague ou pela polêmica.

Mudando o objeto de análise, gostaria de me deter sobre um poema extremamente relevante no conjunto da obra de Jorge de Sena, pelo fato de o seu caráter satírico estar voltado para a mais oficial das figuras portuguesas: Camões. Trata-se do poema "Camões na Ilha de Moçambique", publicado originalmente em edição especial da editora Inova, em 1973, 
como parte do livro Camões dirige-se aos contemporâneos, integrado ainda pelo poema com este mesmo título, publicado originalmente nas Metamorfoses, e pelo conto "Super Flumina Babilonis", constante de Antigas e Novas Andanças do Demônio. É o próprio Sena quem apresenta o poema:

Ao visitar a Ilha que deu o nome ao país, a passagem de Camões por ela inspirou-me um longo poema que era expressão da minha admiração por ele e do meu instinto de ir contra tudo o que tente oficializar seja o que for. Por isso, e creio que com comovida e respeitosa estima, o pus a cagar para o mundo que o lixava e lixa até hoje, com o perdão destas palavras, aliás hoje parte da oratória nacional do mais elevado estilo. ${ }^{15}$

A dessacralização não poderia ser maior. A passagem explica muito do posicionamento geral de Jorge de Sena sobre a arte e sobre o lugar da sátira em sua obra. A sátira da figura camoniana dirige-se menos a Camões do que à cristalização de uma certa imagem do poeta, imagem essa que fala mais sobre a apropriação política do poeta do que de Camões ele mesmo. Oficializar é tornar inerte, incapaz de produzir crítica ou de ser criticado. Ao usar expressões como "comovida e respeitosa estima", Sena deixa claro sobre quem está realmente sendo criticado. E o uso da ironia é extremamente eficiente, pois o grotesco da figura de Camões "a cagar" significa exatamente o contrário, revelando o grotesco de uma outra situação, uma vez que a significação desliza para a expressão "a cagar para o mundo que o lixava e lixa até hoje". O fecho do período explicita uma vez mais, e definitivamente, qual a verdadeira "merda": a contemporânea cultura nacional.

Lembremo-nos de que o poema é de 1972, e seu conteúdo dirige-se à cultura oficial salazarista, que usou e abusou da

${ }^{15}$ SENA, 1973, p. 14. 
imagem de Camões, em especial daquela ligada ao mito do império. Exatamente por isso, Sena coloca Camões na Ilha de Moçambique, imagem histórica das navegações e do império, e, naquele momento da escrita, imagem da guerra anti-colonial que se travava em África. A ironia está também no título geral do volume onde aparece o poema, Camões dirige-se aos contemporâneos, que é por sua vez o nome de um poema de Metamorfoses: contemporâneos de Camões, sim, mas igualmente nossos contemporâneos. O conto "Super Flumina Babilonis" possui o mesmo efeito satírico, alcançado por um caminho diverso. Nesse conto, Camões aparece doente e comicamente dependente da mãe. O efeito satírico humaniza a personagem, e renova o seu poder crítico. Cabe lembrar ainda a grande força pedagógica que a imagem do poeta adquire nesse ato de "dirigir-se" (leia-se "ensinar") aos contemporâneos. Vejamos um trecho do poema:

\section{(...)}

Não de bronze, louros na cabeça, nem no escrever parnasos, que te vejo aqui.

Mas num recanto em cócoras marinhas, soltando às ninfas que lambiam rochas o quanto a fome e a glória da epopéia em ti se digeriam. Pendendo para as pedras teu membro se lembrava e estremecia de recordar na brisa as cróias mais as damas, e versos de soneto perpassavam junto de um cheiro a merda lá na sombra, de onde n'alma fervia quanto nem pensavas. Depois, aliviado, tu subias aos baluartes e fitando as águas sonhavas de outra ilha, a Ilha única, enquanto a mão se te pousava lusa, em franca distracção, no que te era a pátria por ser a ponta da semente dela. (...) 
Ao oficializado Camões de bronze interpõe-se da maneira mais visceral um outro poeta, vivo, a revolver-se intestinamente. A glória da epopéia transforma-se em digestão; versos de soneto estão ao lado de "um cheiro a merda" e as ninfas lambem a matéria fecal. Sobretudo, deve-se notar que a Ilha de Moçambique, assim visceral, reescreve a Ilha dos Amores, de tão puras leituras oficiais e impuros vetos oficiosos, reinscrevendo na consciência do leitor o brilho de humanidade do episódio épico. Essa mesma realidade crua deveria ser cortada das edições destinadas ao público em geral, se fossem seguidas as castas intenções de um crítico salazarista como Álvaro Júlio da Costa Pimpão. Não por acaso, Pimpão e seu sobrenome piada-pronta são alvo de uma das mais ferozes sátiras presentes nas Dedicácias.

Outra imagem radical no poema é a que satiriza as variadas visões da pátria, ali reduzidas ao pênis do poeta. A mais radical afirmação de Sena, através de Camões a se coçar, é a de que a pátria é o corpo, e não o império ou língua. $O$ verso diz, de maneira variada, aquele outro, do poema "Em Creta com o Minotauro", que afirma: "Eu sou eu mesmo a minha pátria". ${ }^{16}$

Aos que esperam sempre a imagem do poeta a produzir parnasos, Jorge de Sena contrapõe um Camões a produzir fezes. A escatologia coloca o poema dentro da tradição satírica que Bakhtin define como sendo o cânon grotesco:

No domínio artístico, conhecemos o cânon clássico, que nos serve de guia até um certo ponto na atualidade; o mesmo não ocorre com o cânon grotesco, que já há muito tempo deixou de ser compreensível ou do qual temos apenas uma compreensão distorcida. A tarefa dos historiadores e teóricos da literatura e da arte consiste em recompor esse cânon, em restabelecer seu sentido autêntico. ${ }^{17}$

16 SENA, 1999b, p. 158.

${ }^{17}$ BAKHTIN, 1993, p. 28. 
Para o crítico russo, o grotesco foi sempre deixado de lado por uma história classicizante da literatura. Somente uma reavaliação do cânon grotesco poderia retirar a tradição literária da mumificação a que ela estaria submetida. $\mathrm{O}$ grotesco bakhtiniano, definido a partir de Luciano de Samósata e de Rabelais, se constitui de toda uma literatura que dá atenção ao corpo, às excrescências corporais, ao sexo, às visões escatológicas, ao palavrão. O grotesco corporificaria uma afirmação da vida, da renovação simbolizada pela primavera. A comida, a bebida, as fezes, o sexo e o riso são as suas marcas.

De maneira reduzida, o projeto de Sena sobre a figura de Camões tem a mesma intenção e efeito. Camões estava, e está ainda, fossilizado sob uma visão classicizante que retira de sua palavra a força crítica. Cabe então dessacralizá-lo, e a estratégia seniana passa pela visão grotesca.

Através da associação entre poesia e fezes, Sena nos leva igualmente a uma reavaliação da noção de poesia. Assim como João Cabral, no poema "Antiode", ${ }^{18}$ Sena propõe que poesia é o que sobra depois da mastigação das palavras e das imagens. Contra uma poesia alada, metafísica, imagem quintessencial do mundo do poeta, Sena, como Cabral, propõe uma poesia humana, no sentido concreto da palavra. Não a flor, mas as fezes.

Ainda que breve tenha sido o percurso aqui empreendido, penso ser possível afirmar a relevância da sátira na poesia de Jorge de Sena, pelo que ela significa sobre o posicionamento do autor diante do ato de escrever e diante da crítica, pensados ambos como práticas interligadas e virtualmente indiferenciadas.

${ }^{18}$ MELO NETO, 1986, p. 332. 


\section{Referências}

BAKHTIN, Mikhail. A cultura popular na Idade Média e no Renascimento. 2. ed. Trad. Yara Frateschi. Brasília/São Paulo: Edunb/Hucitec, 1993. HÍFEN. Lisboa, 6, Fevereiro, 1991.

LISBOA, Eugênio (Org.). Estudos sobre Jorge de Sena. Lisboa: INCM, 1984.

NETO, João Cabral de Melo. "Antiode". In: Poesias Completas. 4 ed. Rio de Janeiro: José Olympio, 1986.

SIMÕES, João Gaspar. Jorge de Sena, o "estrangeirado". In: LISBOA, Eugênio (Org.). Estudos sobre Jorge de Sena. Lisboa: INCM, 1984.

SENA, Jorge de. Camões dirige-se ao contemporâneos. Lisboa: Inova, 1973.

SENA, Jorge de. Maquiavel e outros estudos. Porto, 1974.

SENA, Jorge de. Sistemas e Correntes Críticas. In: Dialéticas Teóricas da Literatura. Lisboa: Edições 70, 1977a.

SENA, Jorge de. O Poeta e o Crítico na Mesma Pessoa. In: Dialéticas Teóricas da Literatura. Lisboa: Edições 70, 1977b.

SENA, Jorge de. O Reino da Estupidez-I. 2. ed., Lisboa: Moraes, 1979. SENA, Jorge de. Pensamento crítico em Portugal. In: Estudos de Literatura Portuguesa-III. Lisboa: Edições 70, 1980a.

SENA, Jorge de. A Crítica Portuguesa no Século XX. In: Estudos de Literatura Portuguesa-III. Lisboa: Edições 70, 1980 b.

SENA, Jorge de. Dedicácias. Edição de Mécia de Sena. Lisboa: Três Sinais, 1999a. $80 \mathrm{p}$.

SENA, Jorge de. "Em Creta com o Minotauro". In: Antologia poética. Edição de Jorge Fazenda Lourenço. Porto: Asa, 1999b, p. 158. Originalmente publicado em Peregrinatio ad loca infecta (1969).

SENA, Mécia de (Org.). Jorge de Sena - Vergílio Ferreira, Correspondência. Lisboa: INCM, 1987.

SENA, Mécia de. Nota Prévia. In: SENA, Jorge de. Dedicácias. Edição . Lisboa: Três Sinais, 1999, p. 10. 


\section{Resumo}

Este artigo visa a uma análise do papel desempenhado pela sátira no conjunto da obra de Jorge de Sena, em especial no livro póstumo Dedicácias, organizado e publicado por Mécia de Sena. A hipótese principal é as de que, através da sátira, Sena cria um elo entre a fatura poética e a atividade crítica. Ao longo do trabalho, são analisados, sob a mesma perspectiva, alguns outros poemas centrais da obra de Sena, tais como "Camões na Ilha de Moçambique" e "Em Creta com o Minotauro".

\section{Abstract}

This paper aims at analysing the role of the genre satyre inside Jorge de Sena's works, specially in the posthumous collection of poems named Dedicácias, edited by his wife and editor, Mécia de Sena. The main hypothesis is that, throughout his entire work, Sena uses satyre to create a link between poetry and criticism. Aside poems from Dedicácias, the paper analyses as well some of the axial poems in Sena's works, such as "Camoes in Mozambique Island" and "In Crete with the Minotaur". 